\title{
PENGARUH KOMPENSASI DAN MOTIVASI TERHADAP KINERJA KARYAWAN KANTOR ESTATE (Studi Kasus Pada PT. Daria Dharma Pratama Air Berau Estate)
}

\author{
Merta Kusuma, Sri Ekowati, Ipan Wahyudi \\ Program Studi Manajemen Universitas Muhammadiyah Bengkulu \\ mertakusuma99@gmail.com; sriekowati@umb.ac.id; ipanwahyudi04@gmail.com
}

\begin{abstract}
ABSTRAK
Merta Kusuma, Sri Ekowati, Ipan Wahyudi; Penelitian ini bertujuan untuk mengetahui pengaruh Kompensasi dan Motivasi Terhadap Kinerja Karyawan Kantor Estate (Studi Kasus Pada PT. Daria Dharma Pratama Air Berau Estate). Populasi dalam penelitian ini adalah 40 orang karyawan kantor estate PT. Daria Dharma Pratama Air Berau Estate. Teknik pengambilan sampel dalam penelitian ini adalah menggunakan sampling jenuh dimana semua jumlah populasi dijadikan sampel yaitu sebanyak 40 orang karyawan. Metode pengumpulan data dengan menggunakan kuesioner. Teknik analisis data yang digunakan adalah regresi linier berganda, koefisien determinasi, dan pengujuan hipotesis. Berdasarkan hasil penelitian dapat dilihat variabel Kompensasi berpengaruh signifikan terhadap Kinerja Karyawan Kantor Estate PT. Daria Dharma Pratama Air Berau estate dilihat dari nilai signifikan sebesar 0,000 lebih kecil dari 0,05. Dan Motivasi berpengaruh karena nilai signifikan sebesar 0,002 lebih kecil dari 0,05. Koefisien determinasi dari R square yaitu sebesar 0,698. Hal ini berarti bahwa Kinerja Karyawan Kantor Estate dapat dijelaskan sebesar $69,8 \%$ oleh variabel independen yaitu Kompensasi dan Motivasi. Sedangkan sisasnya $(100-69,8 \%=30,2 \%)$ dipengaruhi oleh factor-faktor penyebab lain yang tidak diteliti dalam penelitian ini.
\end{abstract}

\begin{abstract}
Merta Kusuma, Sri Ekowati, Ipan Wahyudi; This study aimed to determineThe Effect of Compensation and Motivation toward Employees' Performanceof Estate Office (A Case Study on PT. Daria Dharma Pratama Air Berau Estate). The population of this study were 40 employees of PT. Daria Dharma Pratama Air BerauEstate. The sampling technique of this study was saturated sampling where all the population was 40 employees. The data collection method was a questionnaire. The data analysis techniques of this research used multiple linear regression, coefficient of determination, and hypothesis testing.The results of the study known that the compensation variable has a significant effect toward the performance of Employees at the Estate Office of PT. Daria Dharma Pratama Air Berau estate. It is seen from a significant value of 0.000 less than 0.05 . Motivation is influential because a significant value of 0.002 is smaller than 0.05 . The coefficient of determination of $\mathrm{R}$ square is 0.698 . This means that the Employees' performance of the Estate Office is $69.8 \%$ by the independent variable namely compensation and motivation. While $100-69.8 \%=30.2 \%$ ) are influenced by other causative factors not examined in this study.
\end{abstract}

Keywords: Compensation, Motivation, and Employee Performance.

\section{LATAR BELAKANG}

Sumber Daya Manusia (SDM) adala istilah yang hampir setiap hari didengar dan ditemui. Sumber daya manusia adalah istilah umum yang berkonotasi kepada kemampuan individu dan sekelompok orang yang bekerja dan mengabdi pada suatu perusahaan atau organisasi. Sumber Daya Manusia (SDM) telah menggantikan istilah personalia sebagai penjelasan dari proses dalam mengelola orang (manusia) dalam perusahaan. Dalam mengelola perusahaan dengan baik, banyak sekali upaya yang harus dilakukan dari kesekian banyak upaya tersebut yang menjadi perhatian yang paling pokok adalah kesejahteraan sumber daya manusia. Perusahaan sudah pasti memiliki tujuan dalam setiap pengoperasiannya, tujuan tersebut merupakan pencapaian kinerja yang optimal, dan tentu saja setiap perusahaan memiliki kinerja seseorang yang bekerja didalamnya. Tetapi kinerja tersebut tidak akan diperoleh dengan cuma-cuma apabila kebutuhan karyawan tidak terpenuhi baik kebutuhan biologis maupun psikologis dari karyawan tersebut. Adapun pengertian kinerja merupakan perilaku nyata yang ditapilkan setiap orang sabagai prestasi kerja yang dihasilkan oleh karyawan sesuai dengan perannya dalam perusahaan (Veithzal Rivai: 2011: 548). Salah satu yang dapat mempengaruhi kinerja karyawan dalam perusahaan agar mendorong kinerja karyawan tetap dalam kualitas yang baik adalah kompensasi, dimana diketahui bahwa kompensasi baik itu berupa bonus, gaji, dan segala jenis kompensasi lainnya memiliki pengaruh penting terhadap standar hidup karyawan. Karena hakekatnya tenaga kerja akan lebih produktif apabila tenaga 
kerja tersebut menerima imbalan yang seimbang dengan pekerjaan yang telah mereka kerjakan. Adapun yang dimaksud dengan kompensasi menurut Hasibuan (2016:118) adalah semua pendapatan yang berbentuk uang, barang langsung dan tidak langsung yang diterima karyawan sebagai imbalan atas jasa yang diberikan kepada perusahaan. Dengan kompensasi yang diterima telah sesuai dengan apa yang diharapkan oleh karyawan dalam perusahaan maka karyawan akan berusaha semaksimal mungkin untuk memberikan kinerja terbaiknya.

Factor lain yang juga mempunyai pengaruh terhadap peningkatan kinerja karyawan adalah Motivasi, motivasi merupakan kondisi mental yang mendorong dilakukannya sesuatu tindakan dan memberikan kekuatan yang mengarah kepada pencapaian kebutuhan, kepuasan, motivasi merupakan salah satu hal yang penting dalam kerangka pembangunan sumber daya manusia, karena hal ini berkaitan erat dengan pemimpin dengan yang dipimpin. Seorang pemimpin harus mempunyai cara cepat untuk dapat memotivasi karyawan agar mencapai prestasi kerja yang tinggi. Motivasi sendiri adalah suatu konsep yang diutarakan sebagai kebutuhan (need), keinginan (want), desakan (urge), dorongan (drive), atau implus yang tidak dipisahkan satu dengan yang lainnya, selain terletak pada kemampuannya untuk bekerja juga tergantung pada keinginan mereka untuk bekerja atau tergantung pada motivasinya. Menurut T. Hani Handoko (1998 : 252) Motivasi diartikan sebagai keadaan dalam pribadi sesorang yang mendorong keinginan individu untuk melakukan kegiatan-kegiatan tertentu guna mencapai tujuan. Penelitian ini mencoba untuk mengetahui apakah Kompensasi dan Motivasi berpengaruh terhadap Kinerja Karyawan.

\section{LANDASAN TEORI}

Kinerja Karyawan

Menurut Veithzal Rivai (2011:548) kinerja merupakan perilaku nyata yang ditampilkan setiap orang sebagai prestasi kerja yang dihasilkan oleh karyawan sesuai dengan perannya dalam perusahaan. Kinerja karyawan merupakan hal yang sangat penting dalam upaya perusahaan mencapai suatu tujuan. Menurut Handoko 2002:76 (dalam Muhammad Luthfhi. A) mengistilahkan kinerja (performance) dengan prestasi kerja yaitu proses melalui mana organisasi mengevaluuasi atau menilai prestasi kerja karyawan.

\section{Tujuan Penilaian Kinerja}

menurut Veithzal Rivai (2011:551-553 ) Suatu perusahaan melakukan penilaian kinerja didasarkan pada dua alasan pokok, yaitu : (1) manajer memerlukan evaluasi yang obyektif terhadap kinerja karyawan pada masa lalu yang digunakan untuk membuat keputusan di bidang SDM di masa yang akan datang, dan (2) manajer Memerlukan alat yang memungkinkan untuk membantu karyawan memperbaiki kinerja, merencanakan pekerjaan, mengembangkan kemapuan, dan keterampilan untuk perkembangan karier dan memperkuat kualitas hubungan antar manajer yang bersangkutan dengan karyawannya.

\section{Kompensasi}

Menurut Veithzal rivai (2011:741) Kompensasi merupakan sesuatu yang diterima karyawan sebagai pengganti kontribusi jasa mereka kepada perusahaan. Pemberian kompensasi merupakan salah satu pelaksanaan Fungsi manajemen MSDM yang berhubungan dengan semua jenis pemberian penghargaan individual sebagai pertukaran dalam melakukan tugas dalam organisasi. Adapun yang dimaksud dengan kompensasi menurut Hasibuan (2016:118) adalah semua pendapatan yang berbentuk uang, barang langsung dan tidak langsung yang diterima karyawan sebagai imbalan atas jasa yang diberikan kepada perusahaan.

\section{Tujuan Pemberian Kompensasi}

Samsudin (dalam M. Khadarisman 2012 : 77):

1. Pemenuhan kebutuhan ekonomi.

Karyawan penerima kompensasi berupa upah, gaji, atau bentuk lainnya adalah untuk memenuhi kebutuhan hidupnya sehari-hari atau dengan kata lain, kebutuhan ekonominya. Dengan adanya kepastian menerima upah atau gaji tersebut secara periodic, berarti adanya jaminan "economic Security" bagi dirinya dan keluarga yang menjadi tanggung jawabnya.

2. Meningkatkan produktifitas kerja.

Pemberian kompensasi yang mungkin baik akan mendorong karyawan bekerja secara produktif

3. Memajukan organisasi atau perusahaan.

Semakin berani suatu organisasi memberikan kompensasi yang tinggi, semakin menunjukan betapa makin suksesnya organisasi sebab pemberian kompensasi yang tinggi hanya mungkin apabila pendapatan organisasi/perusahaan yang digunakan untuk itu makin besar. 
4. Menciptakan keseimbangan dan keahlian.

Ini berarti bahwa pemberian kompensasi berhubungan dengan persyaratan yang harus dipenuhi oleh karyawan pada jabatan sehingga tercipta keseimbangan atara input (syarat-syarat) dan output.

\section{Motivasi}

Menurut T. Hani Handoko (1998:252) Motivasi diartikan sebagai keadaan dalam pribadi sesorang yang mendorong keinginan individu untuk melakukan kegiatan-kegiatan tertentu guna mencapai tujuan. Selanjutnya Motivasi adalah serangkaian sikap dan nilai-nilai yang mempengaruhi individu untuk mencapai hal yang spesifik sesuai dengan tujuan individu. (Veithzal Rivai 2011 : 837).

\section{Bentuk atau Faktor - faktor Motivasi}

Bentuk atau factor-faktor motivasi yang digunakan agar karyawan memiliki semangat dan gairah dalam bekerja (Alex 1980) dalam (Windy Aprilia Murty) antara lain :
a. Gaji yang cukup
b. Memperhatikan kebutuhan rohani
c. Menciptakan suasana santai
d. Harga diri perlu mendapatka perhatian
e. Beri kesempatan mereka untuk maju
f. Rasa aman menghadapi masa depan perlu diperhatikan
g. Usaha para karyawan untuk mempunyai legalitas
h. Sesekali karyawan diajak berunding

\section{Kerangka Penelitian}

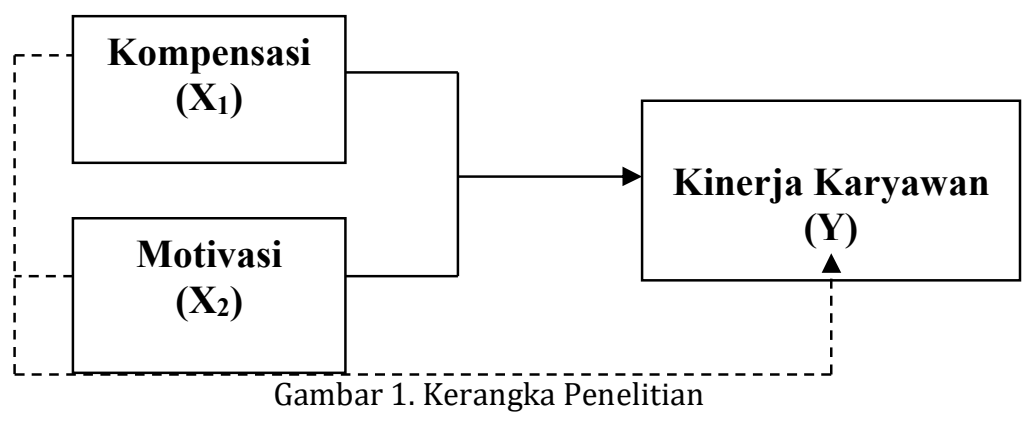

\section{METODELOGI}

\section{Jenis Penelitian dan Teknik Pengumpulan Data}

Jenis penelitian ini merupakan jenis penelitian kuantitatif. "data kuantitatif adalah data yang berbentuk angka, atau data kualitatif yang diangkakan (scoring)" Sugiono (dalam Yuli Suwati : 2013). Penelitian ini dimaksudkan untuk mengetahui adanya pengaruh antara variabel dependen (variabel Terikat) dan variabel independen (Veriabel Bebas). Penelitian ini dilakukan serta difokuskan terhadap karyawaan yang bekerja pada PT. Daria Dharma Pratama.

Dalam penelitian ini menggunakan metode pengumpulan data melalui Kuisioner Adalah teknik pengumpulan data melalui formulir yang berisi pertanyaan-pertanyaan yang diajukan secara tertulis pada seseorang atau sekumpulan orang untuk mendapatkan tanggapan informasi. Bentuk kuesioner bersifat tertutup yaitu responden diberi alternative pilihan jawaban pada setiap pertanyaan. Seluruh variabel akan diukur menggunakan skala likert.

\section{HASIL PENELITIAN DAN PEMBAHASAN Uji Regresi Linier Berganda}

Regresi linier berganda digunakan dalam penelitian ini dengan tujuan untuk mengetahui ada tidaknya pengaruh variabel bebas terhadap variabel terikat mengunakan progam SPSS versi 16.0. 
Tabel 1. Coefficients ${ }^{a}$

\begin{tabular}{|c|c|c|c|c|c|c|}
\hline \multirow{2}{*}{\multicolumn{2}{|c|}{ Model }} & \multicolumn{2}{|c|}{ Unstandardized Coefficients } & \multirow{2}{*}{$\begin{array}{c}\text { Standardized } \\
\text { Coefficients } \\
\text { Beta }\end{array}$} & \multirow[b]{2}{*}{$\mathrm{t}$} & \multirow[b]{2}{*}{ Sig. } \\
\hline & & $\mathrm{B}$ & Std. Error & & & \\
\hline \multirow[t]{3}{*}{1} & (Constant) & 4.398 & 3.912 & & 1.124 & .268 \\
\hline & Kompensasi & .550 & .101 & .591 & 5.476 & .000 \\
\hline & Motivasi & .603 & .186 & .350 & 3.249 & .002 \\
\hline
\end{tabular}

a. Dependent Variable: Kinerja_Karyawan

Interprestasi hasil koefisien regresi pada persamaan diatas adalah sebagai berikut :

1. Nilai konstanta 4.398 mempunyai arti bahwa apabila variabel Kompensasi $\left(\mathrm{X}_{1}\right)$ dan Motivasi $\left(\mathrm{X}_{2}\right)$ terhadap Kinerja Karyawan (Y) sama dengan nol, maka variabel Kinerja Karyawan (Y) akan tetap sama yaitu 4.398. Hali ini berlaku saat dilaksanakannya penelitian.

2. Koefisien regresi variabel Kompensasi $\left(\mathrm{X}_{1}\right)$ 0,550. Hal ini berarti bahwa variabel Kompensasi $\left(\mathrm{X}_{1}\right)$ mempunyai pengaruh positif terhadap Kinerja Karyawan (Y) PT. Daria Dharma Pratama Air Berau Estate. Apabila variabel Kompensasi $\left(\mathrm{X}_{1}\right)$ naik sebesar satu satuan, maka variabel Kinerja Karyawan (Y) PT. Daria Dharma Pratama Air Berau Estate dapat meningkat sebesar 0,550 dengan asumsi Motivasi $\left(\mathrm{X}_{2}\right)$ tetap.

3. Koefisien regresi variabel Motivasi $\left(\mathrm{X}_{2}\right)$ 0,603. Hal ini berarti bahwa variabel Motivasi $\left(\mathrm{X}_{2}\right)$ mempunyai pengaruh positif terhadap Kinerja Karyawan (Y) PT. Daria Dharma Pratama Air Berau Estate. Apabila variabel Motivasi $\left(\mathrm{X}_{2}\right)$ naik sebesar satu satuan, maka variabel Kinerja Karyawan (Y) PT. Daria Dharma Pratama Air Berau Estate dapat meningkat sebesar 0.603 dengan asumsi variabel Kompensasi $\left(\mathrm{X}_{1}\right)$ tetap.

\section{Uji Koefisien Determinasi $\left(R^{2}\right)$}

Tabel 2. Model Summary

\begin{tabular}{|l|r|r|r|r|}
\hline Model & \multicolumn{1}{|c|}{$\mathrm{R}$} & R Square & \multicolumn{1}{c|}{$\begin{array}{c}\text { Adjusted R } \\
\text { Square }\end{array}$} & $\begin{array}{c}\text { Std. Error of the } \\
\text { Estimate }\end{array}$ \\
\hline 1 & $.836^{\mathrm{a}}$ & .698 & .682 & 2.770 \\
\hline
\end{tabular}

a. Predictors: (Constant), Motivasi, Kompensasi

Sumber : Data primer (kuesioner), diolah 2019

Berdasarkan hasil perhitungan dengan menggunakan program komputer SPSS for window versi 16.0 dapat diketahui bahwa koefisien determinasi (R Square) yang diperoleh sebesar 0,698. Hal ini berarti 69,8\% Kinerja Karyawan (Y) dapat dipengaruhi oleh Kompensasi ( $\left.\mathrm{X}_{1}\right)$ dan Motivasi $\left(\mathrm{X}_{2}\right)$ sedangkan sisanya $(100 \%-69,8 \%=30,2 \%)$ dipengaruhi oleh variabel-variabel diluar variabel penelitian ini.

\section{Pengujian Hipotesis Secara Parsial (Uji t)}

Tabel 3. Coefficients ${ }^{\mathrm{a}}$

\begin{tabular}{|rl|r|r|r|r|r|}
\hline & & \multicolumn{2}{|c|}{$\begin{array}{c}\text { Unstandardized } \\
\text { Coefficients }\end{array}$} & \multicolumn{1}{|c|}{$\begin{array}{c}\text { Standardized } \\
\text { Coefficients }\end{array}$} & & \\
\cline { 3 - 5 } Model & & \multicolumn{1}{|c|}{$\mathrm{B}$} & Std. Error & \multicolumn{1}{|c|}{ Beta } & \multicolumn{1}{c|}{$\mathrm{t}$} & \multicolumn{1}{c|}{ Sig. } \\
\hline 1 & (Constant) & 4.398 & 3.912 & & 1.124 & .268 \\
& Kompensasi & .550 & .101 & .591 & 5.476 & .000 \\
& Motivasi & .603 & .186 & .350 & 3.249 & .002 \\
\hline
\end{tabular}

a. Dependent Variable: Kinerja_Karyawan

Berdasarkan pada tabel hasil uji t penelitian ini dapat disimpulkan, sebagai berikut:

1. Variabel Kompensasi $\left(\mathrm{X}_{1}\right)$

Berdasarkan tabel 4.10 pengujian hipotesis dapat diketahui nilai $t_{\text {sig }}$ untuk variabel Kompensasi $\left(\mathrm{X}_{1}\right)$ yaitu sebesar 0,000. Maka dapat disimpulkan $t_{s i g}<\alpha(0,000<0,05)$ yang berarti Ho ditolak dan Ha 
diterima. Jadi terdapat pengaruh yang signifikan antara Kompensasi $\left(\mathrm{X}_{1}\right)$ terhadap Kinerja Karyawan (Y) PT. Daria Dharma Pratama Air Berau Estate.

2. Variabel Motivasi

Berdasarkan tabel 4.10 pegujian hipotesis dapat diketahui nilai $t_{\text {sig }}$ untuk variabel Motivasi $\left(\mathrm{X}_{2}\right)$ yaitu sebesar 0,002. Maka dapat disimpulkan $t_{\text {sig }}<\alpha(0,002<0,05)$ yang berarti Ho ditolak dan Ha diterima. Jadi terdapat pengaruh yang signifikan antara Motivasi $\left(\mathrm{X}_{2}\right)$ terhadap Kinerja Karyawan (Y) PT. Daria Dharma Pratama Air Berau Estate.

\section{Pengujian Hipotesis Secara Simultan (Uji F)}

\section{Tabel 4. ANOVA}

\begin{tabular}{|ll|r|r|r|r|r|}
\hline \multicolumn{1}{|l|}{} & \multicolumn{1}{c|}{$\begin{array}{c}\text { Sum of } \\
\text { Model }\end{array}$} & Squares & df & Mean Square & F & Sig. \\
\hline 1 & Regression & 657.098 & 2 & 328.549 & 42.822 & $.000^{\mathrm{a}}$ \\
& Residual & 283.877 & 37 & 7.672 & & \\
& Total & 940.975 & 39 & & & \\
\hline
\end{tabular}

a. Predictors: (Constant), Motivasi, Kompensasi

b. Dependent Variable: Kinerja_Karyawan

Berdasarkan pengujian dapat diketahui nilai $\mathrm{F}_{\text {sig }}$ untuk variabel Kompensasi $\left(\mathrm{X}_{1}\right)$ dan Motivasi $\left(\mathrm{X}_{2}\right)$ yaitu sebesar 0,000 . Maka dapat disimpulkan $\mathrm{F}_{\mathrm{sig}}<\alpha(0,000<0,05)$ yang berarti Ho ditolak dan Ha diterima. Hal ini berarti bahwa secara bersama-sama Kompensasi $\left(\mathrm{X}_{1}\right)$ dan Motivasi $\left(\mathrm{X}_{2}\right)$ mempunyai pengaruh yang signifikan terhadap Kinerja Karyawan (Y) PT. Daria Dharma Pratama Air Berau Estate.

\section{Pembahasan}

PT. Daria Dharma Pratama Air Berau Estate, Kecamatan Pondok Suguh, Kabupaten MukoMuko. Berdasarkan karateristik respoden berdasarkan jenis kelamin diketahui bahwa karyawan di kantor estate Air Berau didominasi oleh laki-laki dengan persentase 92,5 \% dan perempuan 7,5 \% hal ini karena berdasarkan karakteristik perusahaan merupakan perkebunan kelapa sawit maka laki-laki lebih di percaya karena membutuhkan tenaga yang kuat. Sedangkan berdasarkan usia, usia 20-30 tahun lebih dominan dibandingkan dengan usia lainnya dengan persentase $40 \%$, hal ini karena perusahaan membutuhkan karyawan yang memiliki usia yang produktif. Selanjutnya berdasarkan pendidikan terakhir didominasi oleh pendidikan SMA dibandingkan dengan pendidikan lainnya, hal ini dikarenakan persyaratan berkerja di kantor estate minimal pendidikan terakhir ialah SMA atau sederajat. Dan yang terakhir berdasarkan masa kerja, masa kerja 7-9 tahun lebih dominan dibandingkan dengan masa kerja yang lainnya dengan persentase 37,5 \%, Hal ini dikarenakan perusahaan jarang melakukan rotasi, mutasi dan karyawan memiliki loyalitas kerja yang baik.

Dilihat dari respon Kompensasi ( $\left.\mathrm{X}_{1}\right)$ terhadap Kinerja Karyawan $(\mathrm{Y})$ rata-rata menyatakan baik. Hal ini dikarenakan karyawan puas dengan tingkat gaji secara keseluruhan, menerima pembayaran gaji tepat waktu setiap bulannya, karyawan puas atas kebijakan insentif yang berlaku, karyawan yang berkinerja tinggi diberikan insentif yang sesuai oleh perusahaan, kebijakan perusahaan memberikan bonus kinerja tiap tahun juga dirasa sudah baik, kemudian karyawan menikmati fasilitas asuransi kesehatan yang diberikan, tidak mengalami kesulitan untuk menjalankan hak cuti setiap tahunnya dan karyawan yang memasuki masa pensiun mendapatkan manfaat yang memadai. Selanjutnya kebijakan promosi yang diberikan perusahaan sangat membantu dalam meningkatkan karir, dan karyawan mendapatkan penghormatan dan pengakuan melalui tugas-tugas yang diberikan perusahaan. Selanjutnya jika dilihat dari respon Motivasi $\left(\mathrm{X}_{2}\right)$ terhadap Kinerja Karyawan (Y) rata-rata menyatakan baik. Hal ini menunjukkan bahwa Motivasi di PT. Daria Dharma Pratama Air Berau Estate sudah baik. Dikarenakan dilihat dari kebutuhan akan keberadaan, karyawan bekerja dengan giat untuk memenuhi kebutuhan hidupnya, dengan bekerja di perusahaan akan merasa kehidupan akan terjamin kedepannya. Kemudian dari kebutuhan akan afiliasi karyawan memiliki hubungan komunikasi yang baik dengan sesama rekan kerja maupun atasan. Selanjutnya dilihat dari kebutuhan akan kemajuan karyawan merasa pekerjaan yang dilakukan dihargai oleh atasan, dan menerima ide atau gagasan karyawan yang berkitan dengan pekerjaan. Dan yang terakhir dilihat dari respon kinerja karyawan (Y) rata-rata menyatakan baik. Hal ini menunjukkan bahwa kinerja karyawan PT. Daria Dharma Pratama Air Berau Estate sudah baik, karena dari kuantitas kerja karyawan mampu menyelesaikan pekerjaan lebih banyak dari standart, pekerjaan yang dihasilkan sesuai dangan target yang telah di tetapkan oleh perusahaan, kemudian dari kualitas 
kerja karyawan dapat menyelesaikan setiap pekerjaan dengan teliti dan rapi, menyelesaikan pekerjaan lebih baik dari standar, pekerjaan tidak pernah disalahkan oleh atasan dan karyawan mampu menyelesaikan pekerjaan yang menjadi tanggung jawab yang dibebankan sesuai dengan yang ditentukan perusahaan, lalu dari kehadiran karyawan tidak pernah terlambat masuk kerja, masuk dan pulang kerja sesuai dengan waktu yang telah ditentukan oleh perusahaan. Kemudian dari kemampuan bekerja sama karyawan mampu mengutamakan kerja sama dengan rekan kerja dalam menyelesaikan pekerjaan, dan sering melakukan koordinasi dengan rekan kerja dalam menyelesaikan tugas bersama. Adapun hasil uji hipotesis secara parsial (Uji t) dan uji hipotesis secara simultan (Uji F) dijabarkan sebagai berikut:

\section{KESIMPULAN}

1. Kompensasi $\left(\mathrm{X}_{1}\right)$ berpengaruh positif dan signifikan terhadap Kinerja Karyawan (Y) Kantor Estate PT. Daria Dharma Pratama Air Berau Estate. Hal ini terlihat pada uji t yang menyatakan bahwa Ha diterima dan Ho ditolak. Hal ini berarti bahwa jika Kompensasi ditingkatkan maka akan ada pengaruh yang positif dan signifikan terhadap Kinerja Karyawan Kantor Estate PT. Daria Dharma Pratama Air Berau Estate

2. Motivasi $\left(\mathrm{X}_{2}\right)$ berpengaruh positif dan signifikan terhadap Kinerja Karyawan (Y) Kantor Estate PT. Daria Dharma Pratama Air Berau Estate. Hal ini terlihat pada uji t yang menyatakan bahwa Ha diterima dan Ho ditolak. Hal ini berarti bahwa jika Motivasi ditingkatkan maka akan ada pengaruh yang positif dan signifikan terhadap Kinerja Karyawan Kantor Estate PT. Daria Dharma Pratama Air Berau Estate

3. Kompensasi $\left(\mathrm{X}_{1}\right)$ dan Motivasi $\left(\mathrm{X}_{2}\right)$ berpengaruh positif dan signifikan terhadap kinerja karyawan pada PT. Daria Dharma Pratama Air Berau Estate. Hal ini berarti bahwa jika Kompensasi dan Motivasi ditingkatkan maka akan meningkat pula Kinerja Karyawan Kantor Estate PT. Daria Dharma Pratama Air Berau Estate.

\section{SARAN}

1. Hendaknya Kompensasi yang sudah baik tetap dipertahankan dan lebih ditingkatkan lagi karena faktor ini yang paling dominan memiliki dampak postif dan signifikan terhadap Kinerja Karyawan pada Karyawan Kantor Estate PT. Daria Dharma Pratama Air Berau Estate. Karena karyawan akan memiliki kinerja lebih baik jika mereka mendapatkan apa yang di inginkan setelah melakukan kewajibannya sebagai karyawan. Dan mereka merasa lebih di hargai jika mereka mendapatkan penghargaan oleh pimpinan penghargaan itu salah satunya dapat berupa pemberian kompensasi.

2. Motivasi karyawan Kantor Estate PT. Daria Dharma Pratama Air Berau Estate sudah tergolong baik. Perusahaan hendaknya tetap memperhatikan dan menjaga kondisi motivasi karyawan yang tergolong baik ini melalui pemenuhan kebutuhan dasar karyawan dalam kelangsungan hidupnya seperti memenuhi kebutuhan hidup karyawan melalui gaji atau tunjangan dan jaminan hidup karyawan kedepannya, perusahaaan hendaknya juga tetap memelihara hubungan komunikasi yang baik antar karyawan dan dengan pimpinan dalam pemenuhan kebutuhan karyawan untuk berhubungan komunikasi yang baik dengan orang-orang dilingkungan kerjanya, kemudian pimpinan juga tetap menjaga perhatian terhadap ide atau gagasan yang dikemukakan karyawan dalam upaya melakukan pemenuhan kebutuhan karyawan akan pengaruh yang kreatif dilingkungan kerjanya, sehingga mendorong tingkat kinerja karyawan yang paling tinggi dalam upaya mencapai tujuan perusahaan.

3. Dengan adanya penelitian ini diharapkan bisa menjadi acuan untuk meningkatkan Kinerja Karyawan PT. Daria Dharma Pratama Air Berau Estate.

\section{DAFTAR PUSTAKA}

Diah Indiana Dewi, (2012). Pengaruh Kompensasi dan Penilaian Kinerja Terhadap Employee Engagement di PT. Asuransi Jasa Indonesia (Persero) Kantor Pusat. Tesis. Jakarta : Universitas Indonesia.

Maheswari \& Lutvy. (2017). "Pengaruh Kompensasi Dan Motivasi Terhadap Kinerja Karyawan Pt Bank Ekonomi Raharja Tbk Area Jakarta 5”. Jurnal Manajemen. Volume XIX, No. 02.

Malayu S.P. Hasibuan, (2016). Manajemen Sumber Daya manusia. Jakarta : PT Bumi Aksara.

Muhammad Lutfhi Abizar Gifari Zamhari, (2018), “Analisis Pengaruh Motivasi Kerja, kompensasi dan Disiplin kerja terhadp Kinerja karyawan PT Asia Surya Perkasa pangkal Pinang”. Jurnal ilmiah progresif manajemen Bisnis (JIPMB), volume 25, Nomor 2.

M. kadarisman, (2016). Manajemen Kompensasi. Jakarta : PT Raja Grafindo Persada. 
Sedarmayanti, (2017). Perencanaan dan Pengembangan Sumber Daya Manuia. Bandung : PT. Refika Aditama.

Sugiono, (2013). Metode Penelitian Kualitatif Kualitatif dan R\&D. Bandung: Alfabeta.

T. Hani Handoko, (1998). Manajemen. Yogyakarta : BPFE Yogyakarta.

Usman Fauzi, (2014). "Pengaruh Kompensasi Terhadap Kinerja Karyawan Pada PT. Trakindo Utama Samarinda”. eJournal Ilmu Administrasi Bisnis, 2014, 2 (3) :172-185 ISSN 2355-5408 eJournal.ad.bisnis.fisip.unmul.ac.id.

Veithzal Rivai, (2011). Manajemen Suber Daya Manusia untuk Perusahaan. Jakarta : Rajawali Pers .

Windy Aprilia Murty \& Gunasti, H, (2012). "Pengaruh Kompensasi, Motivasi dan Komitmen Organisasional Terhadap Karyawan Bagian Akuntansi (studi kasus pada perusahaan manufaktur di Surabaya)". The Indonesian Acconting Review, Volume 2, No. 2, july 2012 pages 215- 228.

Yuli Suati, (2013). "Pengaruh Kompensasi dan Motivasi Kerja terhadap Kinerja Karyawan Pada PT. Tunas Hijau Samarinda". eJornal

Usman Fauzi, (2014). "Pengaruh Kompensasi Terhadap Kinerja Karyawan Pada PT. Trakindo Utama Samarinda”. eJournal Ilmu Administrasi Bisnis, 2014, 2 (3) :172-185 ISSN 2355-5408 eJournal.ad.bisnis.fisip.unmul.ac.id. 